\title{
An expedient synthesis of resveratrol through a highly recoverable palladium catalyst
}

\author{
Alejandro V. Martínez $z^{\mathrm{a}}$, José I. García ${ }^{\mathrm{a}}$ and José A. Mayoral ${ }^{\mathrm{a}, \mathrm{b}_{*}}$ \\ ${ }^{a}$ Instituto de Síntesis Química y Catálisis Homogénea (ISQCH). CSIC-Univ. de Zaragoza. Calle Pedro Cerbuna, 12. E-50009 Zaragoza, Spain \\ ${ }^{b}$ Dept. Organic Chemistry, Fac. Sciences, Univ. de Zaragoza. Calle Pedro Cerbuna, 12. E-50009 Zaragoza, Spain
}

Keywords:

Palladium nanoparticles

Supported catalyst

Heck-Mizoroki cross-coupling

Catalyst recycling

Solventless reaction

\section{ABSTRACT}

A straightforward two-step synthesis of resveratrol is described, with total isolated yields in the range of $75-80 \%$. The key synthetic step, a Heck-Mizoroki $\mathrm{C}-\mathrm{C}$ cross-coupling reaction, is efficiently promoted by a heterogeneous catalyst consisting of palladium nanoparticles supported on a synthetic clay. This solid catalyst is quite handy and displays high stability and robustness under reaction conditions. The catalyst can be easily recovered and reused at least ten times, which improves the overall catalytic efficiency of the system. Moreover, the use of solvents is limited, and the reaction procedure allows a facile separation and purification of the desired product, free from the concomitant ionic by-product and from palladium contamination.

\section{Introduction}

Resveratrol ((E)-5-(4-hydroxystyryl)benzene-1,3-diol, 1, Fig. $1)$ is a naturally occurring polyphenolic non-flavonoid compound, representative of a family of substances, known as phytoalexins, which promote the plant protection against attacks by fungi and bacteria. Resveratrol has been isolated from a variety of plants, grape skin, vine bark, nuts, peanuts and berries, among other. This compound has attracted much attention in the last years because the various health benefits it has been claimed to produce, including preventive effects against cancer, inflammation, aging, obesity, cardiovascular diseases, and neurodegeneration, many of them connected to its antioxidant activity. ${ }^{1-3}$<smiles>Oc1ccc(/C=C/c2cc(O)cc(O)c2)cc1</smiles>

Fig. 1. Molecular structure of resveratrol.

As a consequence, there is a current interest in the development of efficient methods for the synthesis of resveratrol and their derivatives. Several synthetic approaches have been described for the synthesis of the title compound. As a trans-stilbene derivative, resveratrol synthesis can proceed through $\mathrm{Wittig}^{4-7}$ or HornerWadsworth-Emmons ${ }^{8}$ reactions, Perkin condensations, ${ }^{9-11}$ and also through metal-catalysed processes, such as cross-metathesis ${ }^{12}$ or cross-coupling reactions. ${ }^{13-23}$
Among them, the latter constitute one of the most straightforward methods to obtain either the target compound or its fully methylated precursor in high yields. Overall yields of the target compound above $70 \%$ have been reported. In most cases, the palladium catalyst necessary for the cross-coupling step is used in homogeneous phase in proportions ranging from 1 to $4 \%$. Studies on the use of recoverable palladium catalysts, however, are rather scarce, in spite of the undeniable interest of minimizing the effective use of palladium. Very recently, Bouchard and coworkers have described the use of a Pd-imine complex immobilized on a MOF as heterogeneous catalysts for the synthesis of the resveratrol precursor (E)-1,3-dimethoxy-5-(4methoxystyryl)benzene. ${ }^{13}$ This catalyst can be used at least ten times, keeping good activity and selectivity. Previously, Ikegami and co-workers had described the use of immobilized palladium species (poly\{dichlorobis[ $[\mathrm{N} \text {-isopropylacrylamide })_{5}$-co-(4-diphenylstyrylphosphine)]palladium $\}) .{ }^{19}$ Unfortunately, the recoverability and reusability of this catalyst was not tested in the case of resveratrol synthesis.

Our group has recently described the use of palladium nanoparticles (PdNP) immobilised on laponite (a synthetic clay) as an efficient and highly recoverable heterogeneous catalysts for Heck-Mizoroki reactions. ${ }^{24-26}$ Up to 75 catalyst uses have been achieved in the case of the reaction between iodobenzene and butyl acrylate, and yet without arriving to an irreversible catalyst deactivation. ${ }^{26}$ In this paper, we describe the use of this catalyst for the synthesis of resveratrol, putting particular emphasis on its recovery and reuse. 


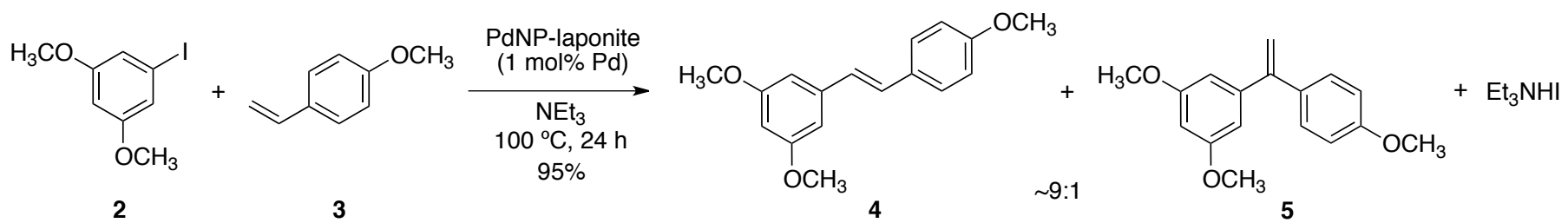

Scheme 1. Pd-catalyzed cross-coupling between 1-iodo-3,5-dimethoxybenzene (2) and 4-methoxystyrene (3)

\section{Results and Discussion}

$\mathrm{Pd}$ nanoparticles were prepared by reduction of $\mathrm{H}_{2} \mathrm{PdCl}_{4}$ with ethanol, in the presence of polyvinylpyrrolidone (PVP), according to previously described procedures. ${ }^{24,27,28}$ The resulting PVPstabilised PdNP were impregnated on laponite clay, using the previously described protocol. ${ }^{26}$ The solid catalyst thus prepared is a free-flowing light-grey solid that can be handled and used without particular precautions. The palladium content of this catalyst is as low as $3 \cdot 10^{-3} \mathrm{mmol} \mathrm{g}{ }^{-1}{ }^{26}$ This catalyst was used to promote the $\mathrm{C}-\mathrm{C}$ cross-coupling between 1-iodo-3,5dimethoxybenzene (2) and 4-methoxystyrene (3) (Scheme 1).

To this end, equimolar amounts of both reagents were adsorbed onto the solid catalyst in the presence of an excess of triethylamine. After reagents and amine adsorption, the system still keeps a fully solid aspect. Then the reaction was heated at 100 ${ }^{\circ} \mathrm{C}$ for $24 \mathrm{~h}$. After this time, the reaction crude was extracted with hexane (but heptane can also be efficiently used for the same purpose) and analysed by gas chromatography. Complete disappearance of the reagents was observed, together with the appearance of two new peaks. The extract was then filtered through silica, evaporated and analysed by ${ }^{1} \mathrm{H}-\mathrm{NMR}$. The NMR spectrum confirmed that the two only reaction products were $(E)$ 1,3-dimethoxy-5-(4-methoxystyryl)benzene (4) and 1,3dimethoxy-5-(1-(4-methoxyphenyl)vinyl)benzene (5), the latter appearing in a small proportion ( $\mathrm{ca} .10 \%)$. The combined isolated yield of $\mathbf{4}+5$ was $95 \%$ (over $85 \%$ of the desired product 4 ). The resveratrol precursor $\mathbf{4}$ was isolated from this mixture by medium pressure column flash chromatography $\left(\right.$ Combiflash $\left.^{\circledR}\right)$, using silica gel as stationary phase and $n$-hexane/ethyl acetate 99:1 as eluent, changing to pure ethyl acetate when the desired product appeared in the eluted fractions (Fig. 2). ${ }^{29} \mathrm{Up}$ to $96 \%$ of the products introduced in the column could be recovered as pure samples.
The recoverability of the catalyst was tested in successive coupling reactions. To this end, after the first reaction, the products were extracted following the above-described protocol, and the solid dried. Then, a new lot of reagents was added, and the reaction repeated in the same conditions. The results of the ten first uses of the catalyst are gathered in Table 1 .

Table 1

Results obtained in the reaction of $\mathbf{2}$ and $\mathbf{3}$ in the successive uses of the same catalyst sample. ${ }^{a}$

\begin{tabular}{cccc}
\hline Run & $\begin{array}{c}\text { Conversion } \\
(\%)^{\mathrm{b}}\end{array}$ & $\begin{array}{c}\text { Isolated yield } \\
(\mathbf{4}+\mathbf{5})(\%)\end{array}$ & $\begin{array}{c}\text { Selectivity to } 4 \\
(\%)^{\mathrm{b}}\end{array}$ \\
\hline 1 & 100 & 94 & 88 \\
2 & 100 & 93 & 87 \\
3 & 100 & 93 & 89 \\
4 & 100 & 96 & 92 \\
5 & 100 & 98 & 89 \\
6 & 100 & 92 & 91 \\
7 & 100 & 99 & 90 \\
8 & 100 & 99 & 89 \\
9 & 100 & 99 & 91 \\
10 & 100 & 90 & 91 \\
Average & 100 & $95.3 \pm 3.3$ & $89.7 \pm 1.6$ \\
\hline
\end{tabular}

\footnotetext{
${ }^{\mathrm{a}}$ Reactions carried out at $100{ }^{\circ} \mathrm{C}$ for $24 \mathrm{~h}$.
}

${ }^{\mathrm{b}}$ Determined as the disappearance of 2 by gas chromatography using $n$ decane as internal standard.

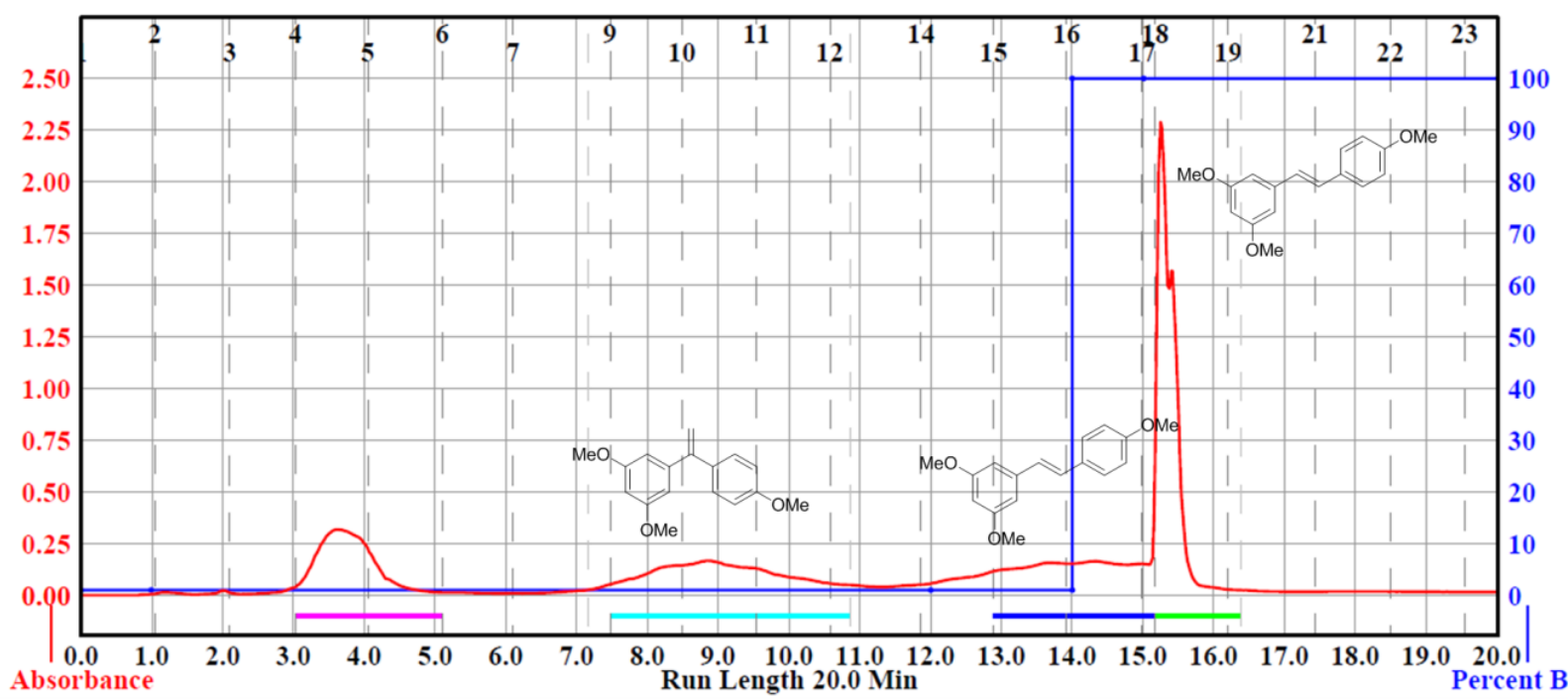

Fig. 2. Flash chromatographic purification of the resveratrol precursor 4 . 
As can be seen, the catalyst displays an excellent performance in the ten first uses, according with our previous findings, surprisingly far better than that previously found for the reaction between 4-methoxystryrene and iodobenzene. ${ }^{26}$ It is also worth noting that the concomitant product, triethylammonium iodide, remains deposited onto the solid together with the catalyst during the product extraction procedure. This helps to obtain the desired product in almost pure form upon extraction, making its isolation easier. On the other hand, after several catalyst uses the mass of ammonium salt exceeds that of the solid catalyst, which makes it difficult catalyst handling and extraction procedures. Fortunately, as we have demonstrated in a previous work, the ammonium salt can be completely eliminated by calcination at $550{ }^{\circ} \mathrm{C}$ under air flow, and the resulting solid still keeps good activity towards cross-coupling reactions. This catalyst reactivation procedure can be used at least three times without loss of catalytic activity and selectivity. ${ }^{26}$ Concerning possible product contamination by palladium, the ICP-MS analyses carried out on the reaction products after flash chromatography did not noticed the presence of $\mathrm{Pd}$ above the detection limit. This point is particularly interesting since it is generally accepted that Pd catalysed CC couplings take place in homogeneous phase, regardless the nature of the catalyst precursor. In the case of Pd-NP, it has been postulated that discrete species of Pd are the true catalyst, and that the nanoparticle acts as a $\mathrm{Pd}(0)$ reservoir. ${ }^{30-35}$ The absence of $\mathrm{Pd}$ in the product means that the aforementioned discrete species either redeposit on the Pd NP (boomerang-like catalyst) or remain adsorbed onto the inorganic support after reaction completion.

The next step for the synthesis of resveratrol consists of methyl deprotection of $\mathbf{4}$ to obtain the free phenol hydroxyl groups, which can be easily accomplished through the use of a Lewis acid, such as boron tribromide, in dichloromethane (Scheme 2). This step proceeds smoothly and with high yields.
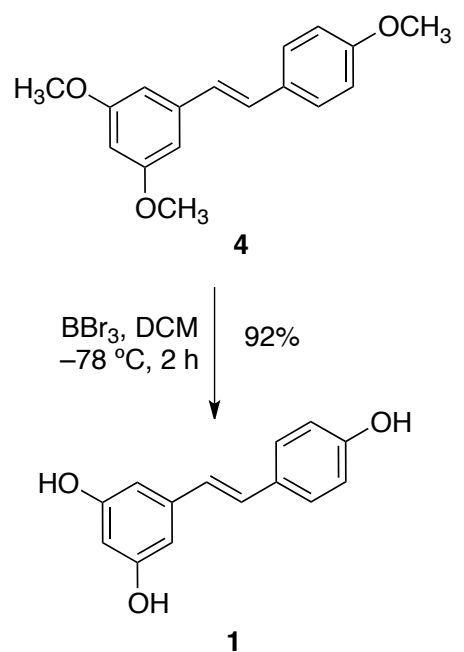

Scheme 2. Deprotection of (E)-1,3-dimethoxy-5-(4-methoxystyryl)benzene (4) leading to resveratrol (1).

\section{Conclusion}

In conclusion, resveratrol can be straightforwardly prepared in pure form in two steps, with a total isolated yield of $c a$. $75-80 \%$. The key synthetic step, a Heck-Mizoroki C-C cross-coupling reaction, is efficiently promoted by a heterogeneous catalyst, consisting of Laponite-supported palladium nanoparticles, which can be prepared in a straightforward way, is easy to handle and use, and shows a high stability and robustness in reaction conditions. Furthermore, as this catalyst can be easily recovered and reused the catalytic efficiency of the system is very high (with only ten uses the effective catalyst concentration per reaction is already as low as $0.1 \%$, and it can be further improved). Moreover, the use of solvent is limited, and the reaction procedure allows a facile separation and purification of the desired product, free from the concomitant ionic by-product.

\section{Experimental section}

All reagents were purchased from commercial sources (SigmaAldrich) and used without further purification, unless otherwise indicated. Although 1-iodo-3,5-dimethoxybenzene (2) is commercially available, it was synthesised from 1-bromo-3,5dimethoxybenzene according to the procedure described in the Supplementary Material. Deuterated solvents were purchased from Aldrich. All analytical pure reagents were used as the only solvents in the reactions. Laponite ${ }^{\mathbb{B}}$ clay was obtained from Rockwood Additives Ltd. Conversions and reaction yields were determined by gas chromatography using Agilent 6809A and 7890A gas chromatographs, provided with FID detectors. Compounds were characterised by NMR spectrometry on a Bruker Avance $400 \mathrm{MHz}$ spectrometer.

\subsection{Preparation of the solid catalyst.}

In a $100 \mathrm{~mL}$ flask, a $2 \mathrm{mM} \mathrm{H} \mathrm{PdCl}_{4}$ solution was prepared by mixing $35.4 \mathrm{mg}$ of $\mathrm{PdCl}_{2}(0.2 \mathrm{mmol}), 2 \mathrm{~mL}$ of $0.2 \mathrm{M} \mathrm{HCl}$, and 98 $\mathrm{mL}$ of $\mathrm{H}_{2} \mathrm{O}$. A mixture of $140 \mathrm{~mL}$ of $\mathrm{H}_{2} \mathrm{O}, 94 \mathrm{~mL}$ of ethanol, 444.6 $\mathrm{mg}$ of poly(vinylpyrrolidone) (PVP) and $100 \mathrm{~mL}$ of the $2 \mathrm{mM}$ $\mathrm{H}_{2} \mathrm{PdCl}_{4}$ solution was refluxed in a $500 \mathrm{~mL}$ flask for $3 \mathrm{~h}$ under air to synthesise the palladium nanoparticles (PdNP) protected by PVP. The black solution was then evaporated at reduced pressure, and the remaining black solid was dissolved in $66 \mathrm{~mL}$ of ethanol. The result was a black stable $3 \mathrm{mM}$ colloidal suspension of palladium nanoparticles in ethanol. $1 \mathrm{~mL}$ of this colloidal suspension was added, together with $6 \mathrm{~mL}$ of dichloromethane, to a $20 \mathrm{~mL}$ Schlenk flask containing $1 \mathrm{~g}$ of Laponite. The resulting mixture was magnetically stirred for $20 \mathrm{~min}$. After that ethanol and dichloromethane were removed under reduced pressure. The result was a powdered light grey solid consisting of the PdNP supported onto the Laponite clay. The ICP-MS analysis of this solid renders a Pd content of $0.305 \mathrm{mg} \mathrm{g}^{-1}$, which is close to the expected theoretical value of $0.318 \mathrm{mg} \mathrm{g}^{-1}$.

\subsection{Procedure for the Heck coupling reactions.}

The reaction mixture, consisting of $79.2 \mathrm{mg}(0.3 \mathrm{mmol})$ of 1 iodo-3,5-dimethoxybenzene (2), $67.1 \mathrm{mg}(0.5 \mathrm{mmol})$ of 1 methoxy-4-vinylbenzene (3) and a $219.6 \mathrm{mg}$ of triethylamine, was prepared in a $5 \mathrm{~mL}$ vial, and then transferred to a $20 \mathrm{~mL}$ Schlenk flask containing $1 \mathrm{~g}$ of the solid catalyst, where the reaction mixture got completely adsorbed. The whole system was then heated to $100{ }^{\circ} \mathrm{C}$ for $24 \mathrm{~h}$. After this time, the reaction was cooled until $65^{\circ} \mathrm{C}$ and then washed with hexane (first $2 \times 10 \mathrm{~mL}$ and then $2 \times 5 \mathrm{~mL}$ ). Finally, the residual solvent on the solid catalyst was removed at reduced pressure. The resulting solid was then ready for further reuse. The hexane extract was analysed by gas chromatography and, after solvent removal, by NMR.

The (E)-1,3-dimethoxy-5-(4-methoxystyryl)benzene product was purified by medium pressure column chromatography (Combiflash ${ }^{\circledR}$ ) using a silica gel column and a mixture hexane /ethyl acetate 99:1 as eluent until the desired product appeared in the collected fractions, and then changing to pure ethyl acetate as eluent. The desired product was isolated $(69.3 \mathrm{mg}, 86 \%)$ as a white solid and characterized by NMR; ${ }^{36}$ [Found C $75.28 \mathrm{H} 6.64$ requires C, 75.53, H, 6.71]; GC conditions: Agilent J\&W CG Column HP$530 \mathrm{~m} \times 25 \mathrm{~mm} \times 0,25 \mu \mathrm{m}$, helium as carrier gas, $230^{\circ} \mathrm{C}$ injector $\mathrm{T}$, $250{ }^{\circ} \mathrm{C}$ detector T, 20 psi head column pressure, $2 \mathrm{~mL} \mathrm{~min}^{-1}$ flux, oven temperature program $70{ }^{\circ} \mathrm{C}(1 \mathrm{~min}), 20^{\circ} \mathrm{C} \mathrm{min}^{-1}, 250^{\circ} \mathrm{C}(7.5$ min), retention time $11.3 \mathrm{~min}$; $\delta_{\mathrm{H}}\left(400 \mathrm{Mhz}, \mathrm{CDCl}_{3}\right) 7.35(\mathrm{~d}, 2 \mathrm{H}$, $J=8.7 \mathrm{~Hz}), 6.95$ (d, $1 \mathrm{H}, J=16.2 \mathrm{~Hz}), 6.83-6.80$ (m, 3H), 6.57 (d, 
$2 \mathrm{H}, J=1.9 \mathrm{~Hz}), 6.29(\mathrm{t}, 1 \mathrm{H}, J=1.8 \mathrm{~Hz}), 3.73(\mathrm{~s}, 9 \mathrm{H}) ; \delta_{\mathrm{C}}(100.6$ Mhz, $\mathrm{CDCl}_{3}$, APT) 161,0 (C), 159,4 (C), 139,7 (C), 130,0 (C), $128,8(\mathrm{CH}), 127,8(\mathrm{CH}), 126,6(\mathrm{CH}), 114,2(\mathrm{CH}), 99,7(\mathrm{CH}), 55,3$ $\left(\mathrm{CH}_{3}\right) ; \mathrm{m} / z(\mathrm{EI}) 270\left(\mathrm{M}^{+}\right)$.

\section{3. (E)-5-(4-hydroxystyryl)benzene-1,3-diol (resveratrol, 1)}

To a solution of $4(270 \mathrm{mg} 1 \mathrm{mmol})$ in $20 \mathrm{~mL}$ of anhydrous dichloromethane at $-78{ }^{\circ} \mathrm{C}, 4.5 \mathrm{~mL}$ of a solution $1 \mathrm{M}$ of boron tribromide in dichloromethane was added dropwise. ${ }^{37}$ The resulting solution was magnetically stirred at $-78^{\circ} \mathrm{C}$ for $2 \mathrm{~h}$. After this time, the solution was let to reach room temperature, and then it was poured onto brine. The organic phase was separated and the aqueous phase was extracted with acetonitrile $(4 \times 30 \mathrm{~mL})$. The combined organic phases were dried with anhydrous $\mathrm{MgSO}_{4}$, filtered and the solvent was removed at reduced pressure. The resulting product was purified by medium pressure column chromatography (Combiflash $\left.{ }^{\circledR}\right)$ using a silica gel column and a mixture hexane /ethyl acetate 1:1 as eluent, leading to a colourless solid (210 mg, 92\%) characterized by NMR $;^{38,39}$ [Found C 73.35 $\mathrm{H} 5.36$ requires $\mathrm{C}, 73.67, \mathrm{H}, 5.30$ ]; $\mathrm{GC}$ conditions: Agilent $\mathrm{J} \& \mathrm{~W}$ CG Column HP-5 $30 \mathrm{~m} \times 25 \mathrm{~mm} \times 0,25 \mu \mathrm{m}$, helium as carrier gas, $230{ }^{\circ} \mathrm{C}$ injector $\mathrm{T}, 250{ }^{\circ} \mathrm{C}$ detector T, $20 \mathrm{psi}$ head column pressure, $2 \mathrm{~mL} \min ^{-1}$ flux, oven temperature program $70^{\circ} \mathrm{C}(1 \mathrm{~min}), 20^{\circ} \mathrm{C}$ $\min ^{-1}, 250{ }^{\circ} \mathrm{C}$ (7.5 min), retention time $12.9 \mathrm{~min}$.; $\delta_{\mathrm{H}}(400 \mathrm{Mhz}$, acetone- $\left.\mathrm{d}_{6}\right) 7.30-7.27(\mathrm{~m}, 2 \mathrm{H}), 6.88(\mathrm{~d}, 1 \mathrm{H}, J=16.3 \mathrm{~Hz}), 6.75(\mathrm{~d}$, $1 \mathrm{H}, J=16.3 \mathrm{~Hz}), 6.71-6.69(\mathrm{~m}, 2 \mathrm{H}), 6.41(\mathrm{~d}, 2 \mathrm{H}, J=2.2 \mathrm{~Hz}), 6.14$ $(\mathrm{d}, 1 \mathrm{H}, J=2.2 \mathrm{~Hz}), 3.64(\mathrm{~s}, 1 \mathrm{H}), 2.88(\mathrm{~s}, 2 \mathrm{H}) ; \delta_{\mathrm{C}}(100.6 \mathrm{Mhz}$, acetone- $\left.\mathrm{d}_{6}, \mathrm{APT}\right) 159.0(\mathrm{C}), 158.2(\mathrm{C}), 140.9(\mathrm{C}), 130.0(\mathrm{C}), 129.1$ $(\mathrm{CH}), 128.7(\mathrm{CH}), 126.6(\mathrm{CH}), 116.4(\mathrm{CH}), 105.7(\mathrm{CH}), 102.7$ $(\mathrm{CH}) ; \mathrm{m} / z(\mathrm{EI}) 228\left(\mathrm{M}^{+}\right)$.

\section{Acknowledgments}

Financial support from the Spanish MINECO (project CTQ2014-52367-R), the European Social Fund (ESF) and the Gobierno de Aragón (Grupo Consolidado E11) is gratefully acknowledged.

\section{References and notes}

(1) Diaz-Gerevini, G. T.; Repossi, G.; Dain, A.; Tarres, M. C.; Das, U. N.; Eynard, A. R. Nutrition 2016, 32, 174-178.

(2) Keylor, M. H.; Matsuura, B. S.; Stephenson, C. R. J. Chem. Rev. 2015, $115,8976-9027$.

(3) Quideau, S.; Deffieux, D.; Douat-Casassus, C.; Pouységu, L. Angew. Chem. Int. Ed. 2011, 50, 586-621.

(4) Ismail, T.; Shafi, S.; Srinivas, J.; Sarkar, D.; Qurishi, Y.; Khazir, J.; Alam, M. S.; Kumar, H. M. S. Bioorganic Chem. 2016, 64, 97-102.

(5) Alonso, F.; Riente, P.; Yus, M. Eur. J. Org. Chem. 2009, 6034-6042.

(6) Alonso, F.; Riente, P.; Yus, M. Tetrahedron Lett. 2009, 50, 3070-3073.

(7) McNulty, J.; Das, P. Eur. J. Org. Chem. 2009, 4031-4035.

(8) Birar, V. C.; Sheerin, A. N.; Milkovicova, J.; Faragher, R. G. A.; Ostler, E. L. Chem. Cent. J. 2015, 9, DOI 10.1186/s13065-015-0102-7.

(9) Sinha, A. K.; Kumar, V.; Sharma, A.; Sharma, A.; Kumar, R. Tetrahedron 2007, 63, 11070-11077.

(10) Kumar, V.; Sharma, A.; Sharma, A.; Sinha, A. K. Tetrahedron 2007, 63, 7640-7646.

(11) Solladié, G.; Pasturel-Jacopé, Y.; Maignan, J. Tetrahedron 2003, 59, 3315-3321.

(12) Ferré-Filmon, K.; Delaude, L.; Demonceau, A.; Noels, A. F. Eur. J. Org. Chem. 2005, 3319-3325.

(13) Brown, J. W.; Jarenwattananon, N. N.; Otto, T.; Wang, J. L.; Glöggler, S.; Bouchard, L.-S. Catal. Commun. 2015, 65, 105-107.

(14) Lara-Ochoa, F.; Sandoval-Minero, L. C.; Espinosa-Pérez, G. Tetrahedron Lett. 2015, 56, 5977-5979.

(15) Perez, C. C.; Pena, J. M.; Correia, C. R. D. New J. Chem. 2014, 38, 3933-3938.

(16) Schmidt, B.; Elizarov, N.; Berger, R.; Hölter, F. Org. Biomol. Chem. 2013, 11, 3674-3691.

(17) Nobre, S. M.; Muniz, M. N.; Seferin, M.; da Silva, W. M.; Monteiro, A. L. Appl. Organomet. Chem. 2011, 25, 289-293.
(18) Moro, A. V.; Cardoso, F. S. P.; Correia, C. R. D. Tetrahedron Lett. 2008, $49,5668-5671$.

(19) Yamada, Y. M. A.; Takeda, K.; Takahashi, H.; Ikegami, S. Tetrahedron 2004, 60, 4097-4105.

(20) Botella, L.; Nájera, C. Tetrahedron 2004, 60, 5563-5570.

(21) Jeffery, T.; Ferber, B. Tetrahedron Lett. 2003, 44, 193-197.

(22) Andrus, M. B.; Liu, J.; Meredith, E. L.; Nartey, E. Tetrahedron Lett. 2003, 44, 4819-4822.

(23) Guiso, M.; Marra, C.; Farina, A. Tetrahedron Lett. 2002, 43, 597-598.

(24) Martínez, A. V.; Mayoral, J. A.; García, J. I. Appl. Catal. Gen. 2014, $472,21-28$.

(25) Martínez, A. V.; Invernizzi, F.; Leal-Duaso, A.; Mayoral, J. A.; García, J. I. $R S C A d v$. 2015, 5, 10102-10109.

(26) Martínez, A. V.; Leal-Duaso, A.; García, J. I.; Mayoral, J. A. RSC Adv. 2015, 5, 59983-59990.

(27) Teranishi, T.; Miyake, M. Chem. Mater. 1998, 10, 594-600.

(28) Li, Y.; Boone, E.; El-Sayed, M. A. Langmuir 2002, 18, 4921-4925.

(29) As a referee pointed out, the resveratrol precursor appears depicted twice on the chromatogram in Fig. 2, which may result confusing at the first sight. In fact, the red line in the figure represents the UV absorbance of the sample, and the blue line the composition of the eluent. The resveratrol precursor starts leaving the column in the minute 12 , at a low concentration. In the minute 14 , the eluent is changed to pure ethyl acetate, which provokes that most of the resveratrol precursor was collected in the fractions between the minute 15 and the 16 . There are no two separated peaks, but one irregularly shaped peak representing different concentrations of the target compound in the collected fractions due to the different polarity of the eluent.

(30) Gruber, A. S.; Pozebon, D.; Monteiro, A. L.; Dupont, J. Tetrahedron Lett. 2001, 42, 7345-7348.

(31) Alimardanov, A.; Schmieder-van de Vondervoort, L.; de Vries, A. H. M.; de Vries, J. G. Adv. Synth. Catal. 2004, 346, 1812-1817.

(32) Cassol, C. C.; Umpierre, A. P.; Machado, G.; Wolke, S. I.; Dupont, J. J. Am. Chem. Soc. 2005, 127, 3298-3299.

(33) Astruc, D. Inorg. Chem. 2007, 46, 1884-1894.

(34) Dupont, J.; Scholten, J. D. Chem. Soc. Rev. 2010, 39, 1780-1804.

(35) Scholten, J. D.; Leal, B. C.; Dupont, J. ACS Catal. 2012, 2, 184-200.

(36) Lebel, H.; Ladjel, C.; Bréthous, L. J. Am. Chem. Soc. 2007, 129, 1332113326.

(37) Pettit, G. R.; Grealish, M. P.; Jung, M. K.; Hamel, E.; Pettit, R. K.; Chapuis, J.-C.; Schmidt, J. M. J. Med. Chem. 2002, 45, 2534-2542.

(38) Lee, D.; Bhat, K. P. L.; Fong, H. H. S.; Farnsworth, N. R.; Pezzuto, J. M.; Kinghorn, A. D. J. Nat. Prod. 2001, 64, 1286-1293.

(39) Csuk, R.; Albert, S.; Siewert, B.; Schwarz, S. Eur. J. Med. Chem. 2012, $54,669-678$. 